\title{
Refugee Education: The State of Nigeria's Preparedness
}

\author{
Oluwayemisi A. Obashoro-John, Gbolabo J. Oni* \\ Department of Adult Education, University of Lagos, Nigeria
}

Copyright $(2017$ by authors, all rights reserved. Authors agree that this article remains permanently open access under the terms of the Creative Commons Attribution License 4.0 International License

\begin{abstract}
The spate of insurgences and conflicts in the country and around the sub-region has led to the increased presence of refugees and Internally Displaced People (IDPs) in Nigeria. This has resultant challenges on the basic needs of refugees and IDPs at different levels. One of the highest priorities of refugees and IDPs communities is education. Nigeria is obviously struggling to provide basic education for her citizens hence the emergence of refugees and IDPs and their need for education put a double burden on the nation's education system. Sections of the 1948 Universal Declaration of Fundamental Human Rights; 1951 Convention on the Status of Refugees, 1989 Convention on the Rights of the Child, and 1990 Declaration of World Conference on Education for All call for no discrimination in the education of men, women and children irrespective of status; compulsory and free education for all and the right to education in emergencies. These are supposed to be the policies and implementation guidelines for ratifying countries. Observations show that, in spite of the challenging situation, there is little evidence of the commitment by the Nigerian government through the Universal Basic Education Commission (UBEC) to the education of refugees and IDPs. In cases where some levels of provisions are available, the quantity and quality of such provisions needs improvements. Since there is no guarantee that refugees problems will end soon, this paper examines the available provisions and institutional approaches for the education of refugees and IDPs in Nigeria; analyses the level of Nigeria's preparedness for providing education for refugees and IDPs persons; and makes propositions for meeting this peculiar global reality.
\end{abstract}

Keywords Refugee, Refugee Education, Nigeria's Preparedness

\section{Introduction}

Political instability, resulting from inter-state and intra-state conflicts, characterizes much of Africa. It is perhaps why Africa has been described as the "continent of refugees". As uncomplimentary as this may sound, the fact is that nearly every country in Africa has experienced one form of civil strife creating a huge refugee problem for the continent. Pogroms that happened in Rwanda, Burundi, Democratic Republic of Congo, Somalia, Sudan, Liberia, Sierra Leone, Côte d'Ivoire and Nigeria seem to lend credence to the unsavoury label. In some instances, problems in sub- regions have had wider implications on the whole region.

Countries in Africa are weighed down by rapid population and unemployed labour force, declining agricultural productivity and increasing rural exodus to urban areas. Literature reveals that the twenty first century Africa has come to a crossroad, economically, politically and demographically... "known as a region of great diversity in terms of history, culture, colonial experience, socio-political systems, population size and patterns of development, it is also a continent of contradictions - rich in resources while its people are becoming poorer by the day" (Adepoju, 2010). Political, economic and social upheavals, bad governance added to natural disasters have been identified as major causes that sustain the situation. The magnitude of communal and ethnic warfare on the continent and other reasons has significantly intensified displacements and refugees crisis in Africa. These in recent times have attained alarming proportions resulting in recognizable devastating effects on the national, economic, social and political life of both the host countries and the refugees. The United Nations High Commission for Refugees (UNHCR, 2014) and African Renewal (2016) statistics states that there are 38.2million people displaced worldwide with Africa's share being about 12 million and Nigeria having about 3.3million.

The African refugee population is increasing and it poses a dilemma for various actors and stakeholders such as governments, international organizations, agencies, host countries and the refugees. A careful study of the categories of refugees shows that various factors combine in different measures and environments to sustain the increasing number of refugees seen across the various regions of the world. The United Nations 1951 Refugee Convention describes a refugee as someone who

"owing to a well-founded fear of being persecuted for reasons of race, religion, nationality, membership of a particular social group or political opinion, is outside the country of his nationality, and is unable to, or owing 
to such fear, is unwilling to avail himself of the protection of that country'. (UNHCR, 1967)

International refugee law defines a refugee as 'someone who seeks refuge in a foreign country

because of war and violence, or out of fear of persecution'.

Internally displaced persons are similar to refugees, but they are people who have not crossed any international borders (are displaced within their own countries).

The types of refugees found in literature are:

- Refugees created by human conflicts - "crises refugees"

- Refugees created by natural and environmental disturbances - 'environmental refugees'

- Refugees created by economic circumstances. These are products of situations in which people are unable to support themselves in their places of abode and move in search of greener pastures (Oluyemi- Kusa, 2010).

These definitions view refugees from racial, religion, political and social perspectives. Many events thereafter have added to emergent factors that turn people to refugees. Some of these problems are usually geographical or limited to groups but varies from one country to another. Factors such as ecological problems, ethnic discrimination or cleansing, religion, poverty, misinformation, cultural threat and discrimination in the case of HIV/AIDs victims may be added. When such people move across borders they become refugees. However, when they remain within the borders of their countries of location, they are referred to as Internally Displaced Persons (IDPs).

The spectre of world terrorism and sectarianism of various shades has ravaged several countries turning millions of people to either refugees or IDPs. The activities of ISIS in Iraq and Syria; Al Shabah in Somalia and Boko-Haram in Nigeria and the West African sub-region have created a flood of refugees and IDPs in the regions mentioned.

\section{The Nigerian Situation: Locations and Figures}

Nigeria consists of many cultures and ethnic and sub-ethnic groups who practice different types of religions. Literature reveal (Eze, Okpala \& Ogbodo; 2014) that there are approximately 400 ethnic groups and 450 languages in Nigeria. This peculiar circumstance and subsequent ethno-religious conflicts is reflected in the Boko Haram insurgency which surged the population of IDPs in Nigeria (New York Times, 2015). The problem of refugees and IDPs in Nigeria started when these insurgents took over large areas of the North Eastern part of Nigeria and forced millions of people (men, women and children) to flee their homes. This compelled government to set up camps to accommodate them to ensure their wellbeing.

Currently, displaced persons live in 32 formal camps, host communities and satellite camps in different States Northern Nigeria. Popular among these with available figures

$\begin{array}{lll}\text { Borno } & -1,158,362 ; & 19 \text { camps } \\ \text { Ngala } & -70,505 & \\ \text { Dikwa } & -53,636 & \\ \text { Bama } & -27,000 & \\ \text { Damboa/Sabon Gari } & -25,311 & \\ \text { Adamawa } & -125,689 ; & 4 \text { camps } \\ \text { Yobe } & -107,562 ; & 9 \text { camps }\end{array}$

(www.vanguardngr.com, April 2016)

Figures based on an assessment conducted from November to December 2015 by the International Organization for Migration's (IOM) Displacement Tracking Matrix (DTM) team in 207 Local Government Areas (LGA) covering 13 States of Northern Nigeria:

Abuja (13,481 IDPs);

Adamawa (136,010);

Bauchi (70,078);

Вепие (85,393);

Borno $(1,434,149)$

Gombe (25,332);

Kaduna $(36,976)$;

Kano (9,331);

Nasarawa (37,553);

Plateau (77,317);

Taraba (50,227);

Yobe (131,203);

Zamfara $(44,929)$

(IOM/NEMA, 2016) 

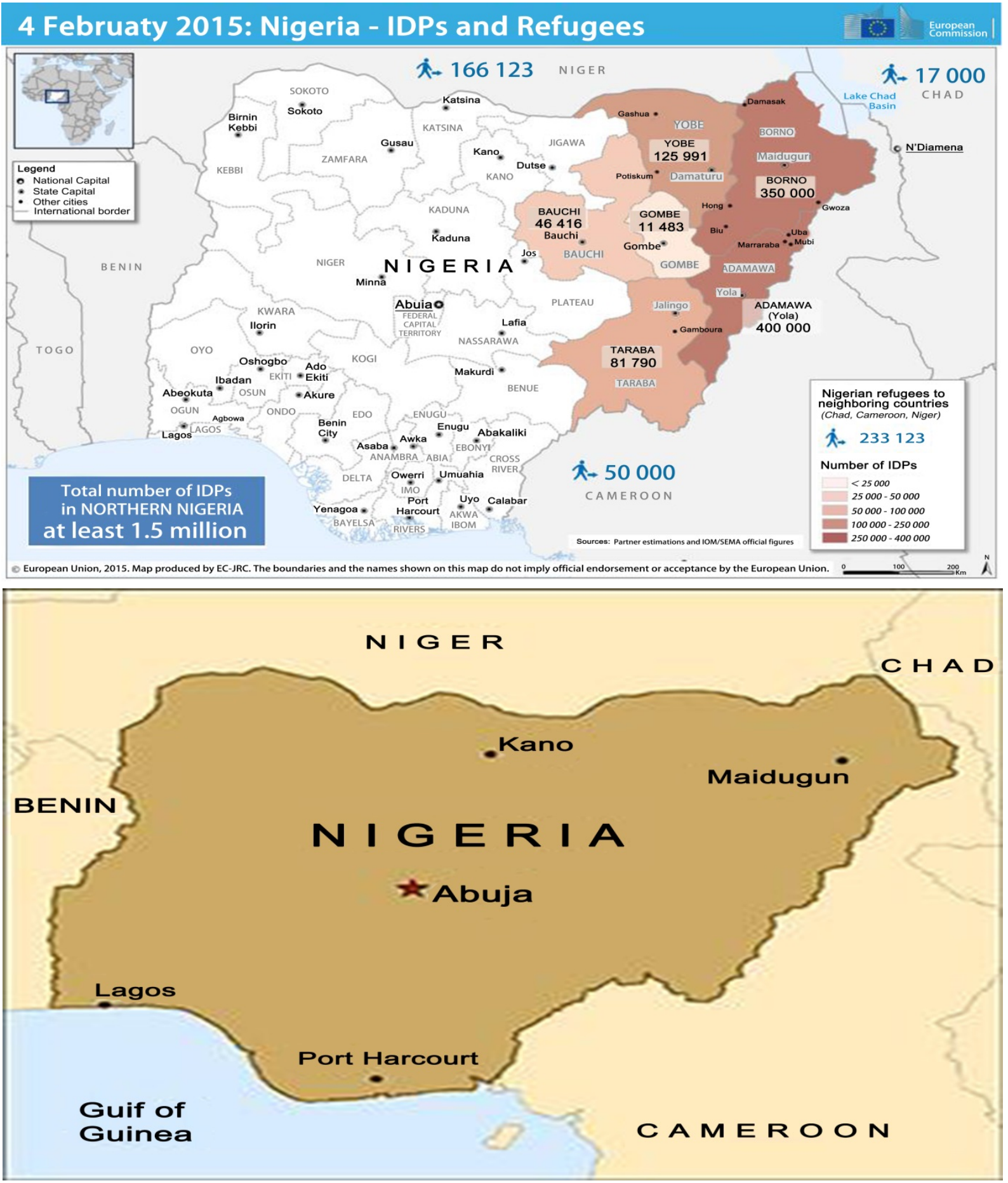

There is no gainsaying that the presence of refugees or internally displaced persons in any country has direct effects on the country's finances and infrastructure. The case of Nigeria is further accentuated with the downturn in its economic fortunes with the global decline in crude oil prices and the recent bombing activities of militants in the Niger Delta region, from where the bulk of her earnings and revenues are derived. This is further compounded by the activities of rampaging Fulani herdsmen, who are causing considerable displacement of persons from their communities.

Nigeria, especially since the commencement of the Boko Haram insurgency in the North East and communal clashes has had to grapple with the problem of developing systems and processes of crisis response mechanisms to solve resultant problems. It should be noted that Nigeria fought a bitter civil war between 1967 and 1970 without any form of borrowing because she had a very healthy economic circumstance during this period. The country's economic situation today is completely different and it is not 
unexpected that her ability to intervene and level of preparedness to adequately and effectively respond to the challenge of refugees and internally displaced persons may be seriously hampered.

\subsection{Education and Refugee Education}

For those who have practically lost all other assets, education represents a primary survival strategy which forms the basis to build livelihood and reintegration. Education seen as a basic right is enshrined in the 1989 Convention on the Rights of the Child, the 1951 Refugee Convention and the National Policy on Education (NPE; 1977, 1981, 1998 and 2004) as well as the 2000 Universal Basic Education (UBE) Policy in Nigeria.

The sole aim of basic education in Nigeria is to equip individuals with knowledge and skills that will enable them to

a live meaningful and fulfilling lives;

b contribute to the development of the society;

c derive maximum social, economic, and cultural benefits from the society;

d discharge their obligations competently (FME,1999.)

It may be implied from the above stance on basic education that the UBE is expected to provide free and compulsory education for all including special groups, refugees.

Refugee education is meant to foster social cohesion, provide access to life-saving information, address psychological needs and offer and stable environment for these persons referred to as refugees. It is to help these rebuild their lives, communities and direct energies towards productive and meaningful lives.

Refugee education requires professionals in all aspects of education relevant to develop the vital learning domains which include basic knowledge, technical or job related skills, positive attitudes, inter-personal relationship and productive consciousness, for personal and communal efficiency.

Education is a vital tool for individual, community, and national development. The objectives of education in countries are directly situated within their overall National Development Plans. These apply to internally displaced persons.

For most refugees and internally displaced persons, education, whether basic literacy or skill based training may help to put life into their seemingly dead situations. The level of preparedness for refugee education is dependent on the economic circumstances of the nation especially as most to the camps hosting the IDPs are managed by a central agency, the National Emergency Management Agency (NEMA). NEMA is directly funded by the Federal Government despite recession. Taking into consideration the fact that there is a generally acknowledged deficit in Nigeria's education infrastructure and its inability to provide most basic requirements for the education sector, the level of preparation for refugee education may suffer greater deficit.

A country's level of preparation is expected to meet at least the basic demands of refugee education and show her ability to adequately and proactively deploy resources to meet emergency situations as they arise. The typical response to refugee situations is to focus on relief materials such as food, clothing and medical supplies. To a large extent, Nigeria has shown preparedness in these areas.

Nigeria has been generously described by some scholars as a developing country. Less generous analysts have, however, referred to the country as an under-developed country. This description undoubtedly derives from its very low level of social and economic infrastructure, which directly impact on the standard of living of the majority of her population.

The submission in this paper is that the level of preparedness for refugee education must be situated against the background of the country's present economic circumstances and her ability to effectively address any form of disasters and emergencies.

A reality of assessment of Nigeria's preparedness is that there is a lot that still needs to be done to bring us to the required level. The President of Nigeria visited one of the IDP camps in the North Eastern geo-political zone towards the end of year 2015. Nigerian newspapers were awash with news about the parlous state of the camp, which is symptomatic of most of such camps. Infrastructure is lacking and the state of the inhabitants of the camps is considered as very poor.

Mass and social media images show the conditions of most refugee camps and the living status of refugees. Even those in developed economies, cannot be said to be fully prepared to cover the social and education needs of refugees.

\subsection{Hyperlink Pictures}

Refugees and other displaced persons, however, require more than relief. They require support to be able to continue with life and relatively good living. Adult, adolescent and children refugees or internally displaced persons share common characteristics, which include the disruption of their education or business. This has considerable implications on their psyche, which calls for specialists' support. The kind of education proposed for such persons must be functional and not merely academic or basic literacy.

To be able to achieve the major objective of ensuring basic education for refugees and displaced persons, the United Nations in 2010 passed the resolution on the right to education in emergencies. Following this, the Interagency Network on Education in Emergencies (INEE) in collaboration with other committed groups developed these four tools to assist. They are

a INEE and IASC Education Cluster's Module 14: Human Rights and Accountability.

b The INEE Minimum Standards for Education, Preparedness, Response, Recovery. 
c The INEE Teaching and Learning Guidance Notes.

d The INEE Reference Guide on External Education Financing.

The major objective is to ensure that refugees have access to basic education. The situation of the refugee is an unusual one caused by decisions and actions to which he is not a party. Much as the situation is external to the refugee some form of coercion is also exerted over him or her and the pain the refugee feels can only be assuaged through appropriate psycho-social and educational measures.

At the individual level, refugee education can focus on productive activities, which may be in the informal sector. In as much as a future without wars and natural disasters is desirable, it may be far-fetched. Refugee situations will necessarily be disrupted hence efforts must be deliberately made to ameliorate the impact of disruptions and restore the psycho-social balance of the refugees and displaced persons. It is necessary that efforts be directed at formal education for children and non-formal for adults.

Refugee education can be treated as an emergency where there are military conflicts to include refugees, soldiers and fighters. It can be structured to cover all parties involved. Soldiers and fighters can be taught to respect the rights of refugees and displaced persons.

Educators involved with refugees can devise means of providing temporary classrooms and improvise to meet peculiar needs of refugees. They may be able to support the refugees psychologically and create a feeling of hope for the future after the current emergency.

The overall objective of refugee education is to improve their living standard and socio-economic circumstances. We must be always reminded that the situation of the refugee is an unusual one caused by decisions and actions which they may not be party to. Refugee education may not be limited to just formal education but an attempt to impact knowledge in all areas of life which will enable the refugee develop skills for independence.

Action plan for refugee education is akin to preparation for natural disasters like hurricanes or mudslides because they may occur without warnings and their impacts inform human and social crises. Observations show that politically motivated instability, ethnic and religious uprising build up with time and explode with consequent social crises, in some cases, refugee issues. The case of Boko Haram and the resultant IDPs situation in Nigeria buttress this perspective. Action plan may therefore consider many aspects of the structural and institutional capacity of the country. Further considerations may be given to the psychological status and geographical location of the refugees and camps. It may not be out of place to commit to

- Training of citizens for multi-tasks in all circumstances

- Participation of faith-based and philosophical organizations in citizenship education

- Planned logistics for stewards and use of regional resources
- Regionalization of emergency relief organizations for prompt intervention

- Partnership with international relief organizations in peace time

- Regionalization of emergency relief materials for easy distribution

- Occasional drills and monitoring of social trends in politics, economy and social relationships.

\section{Conclusions and Recommendations}

Nigeria being the largest country in Africa is naturally a major player in the affairs of the continent. Nigeria has served as a place of refuge for person's fleeing armed conflicts and economic and political problems across the continent. In the mid and late 1970s, the country actively provided refuge for citizens of Angola, Mozambique, Namibia, South Africa and Zimbabwe fighting for political independence.

Though Nigeria has provided relief and support in times of crises and emergencies, yet the majority of refugees do not receive basic education. Literature reveals that of the approximately 20 million refugees under the care of the UNCHR, half are children below 18 years; only $50 \%$ of the children are enrolled in primary education; $25 \%$ in secondary education and $1 \%$ have access to tertiary education. These figures include those from Nigerian where accurate data estimations are not available. This situation requires concerted efforts of governmental and non-governmental bodies. Preparations should include but not limited to the following:

- Practitioners are advised to devise strategies that will allow the sharing and exchange of knowledge and skills that refugees are carrying from their homelands.

- Since resources and supplies are limited, provisions of vocational and entrepreneurial training for employment to meet personal and family sustenance requirement are to be intensified.

- Often the class sizes are large with learners who are of varying educational backgrounds, language skills and ages. Teachers are to be supported and trained to meet the challenges of teaching in refugee communities.

- Teachers and other professionals are likely to be among the refugees or IDPs. Identify teachers in the population who may organize educational and recreational activities and support informal educational groups organized by refugees and displaced persons themselves.

- It is therefore imperative that international organizations, foundations and developed countries offer assistance and support the country to improve on its preparedness through building the capacity of specialized teachers.

- Where applicable and practicable, anticipatory training may be given to teachers on the educational tools 
developed by INEE in readiness for use when required.

\section{REFERENCES}

[1] Patrick, M. \& Ijah, C.N (2012). Adult and Non-Formal Education Programmes of Non-Governmental Organizations for Poverty Alleviation in Nigeria: What can be learnt from the Practice? Journal of Education and Practice (Paper) ISSN 2222-288X (Online) Vol. 3, No 11, 2012 (1)

[2] Internal Displacement Monitoring Centre (IDMC) Nigeria IDP Figures Analysis Switzerland Retrieved 20/6/2016

[3] Convention and Protocol Relating to the Status of Refugees (PDF) Geneva Switzerland: Office of the United Nations High Commissioner for Refugees (UNHCR), Communications and Public Information 1967. Retrieved 6/6/2016

[4] Adepoju A. (2010), International Migration to and from Africa in a Globalized World. Ghana Sub-Saharan Publishers

[5] Oluyemi-Kusa, Dayo (2010). The African refugee phenomenon. Lagos: Malthouse Press Limited, (Edited)

[6] Blanning, T.C.W. (1986). The origin of the French Revolutionary War. London \& New York: Longman.

[7] Kivistor P. (2012). Refugee. In The Willey-Blackwell Encyclopedia of Globalization. Ritzer, G. (ed.). Malden, M.A; Wiley-Blackwell.

[8] Shapiro, Ronald M. (2009). Dare to Prepare: How to Win Before You Begin. Crown Publishing Group

[9] Haddad, E. (2008). The Refugee: Individual between Sovereigns. Global Society.

[10] Nikita M. (2014). Lebanon's Limited Educational Infrastructure for Syria's "Lost Generation". I www.brownpoliticalreview.com Retrieved September 25th, 2014

[11] Geertz, C. (1973). The Interpretation of Cultures. New York, Free Press.

[12] Israel, R. C. (2012). "What Does it Mean to be a Global Citizen?" Kosmos.

[13] Miriam, A. (2014). Bringing learning to Syrian refugee children in Lebanon. In http://www.unicef.org/infobycountry/lebanon

[14] Ohmae, K. (2005) The End of the Nation Staes. In F.J. Lechner and J. Boli (Eds); The Globalization Reader. Oxford: Blackwell Publishing.

[15] UNHCR: Refugee protection: A Guide to International Refugee Law, 2001

[16] UNHCR, April 3, May 2014. Syrian refugees in Lebanon surpass one million.

[17] UNHRC, (2014). Barrier to Education for Syrian Refugee Children in Lebanon: Out of School Profiling. UNHRC.
[18] Wright, J.K. 1947. Terrae Incognitae: The Place of Imagination in Geography Annals of the Association of American Geographers 37: 1-15.

[19] UNICEF Factsheet, May 16, 2014

[20] Reser, J.P. (2007). Psychology and the Natural Environment. A Position Statement prepared for The Australian Psychological Society in September, 2007.

[21] United National High Commission for Refugees, (2006). Refugees: Flowing Across Borders. UNHCR.

[22] Srinivasan, S. (2013). The Politics of Negotiating Peace in Sudan. In Peace Building, Power and Politics in Africa. (Devon, C. and Gwinyayi, A.D. Eds.) Wits University Press, Ohio, USA.

[23] Eze, T. C., Okpala, C. S., Ogbodo, J. C. (2014). "Patterns of Inequality in Human Development Across Nigeria's Six Geopolitical Zones". Department of Economics, Caritas University, Amorji-Nike, Emene, Enugu State.

[24] Florek, M. (2011). "No place like home: Perspectives on place attachment and impacts on city management". Journal of Town \& City Management. United Nations High Commission for Refugees, (2014)

[25] United Nations Africa Renewal, (2016). Africa's Displaced People: Out of the Shadows: Strategic Communications Division, Department of Public Information, United Nations.:http://www.un.org/africarenewal/magazine/april201 0/Africa. Retrieved 30/04/2016.

[26] Deng, F. (2007). "The guiding principles on internal displacement", February 11. New York, NY: United Nations. New York: United Nations. Retrieved 05-10-2016.

[27] The Guardian Newspaper, (Februaury 23rd, 2016). Borno Moves 4,500 IDPs to Camp to Reopen Schools. Page 11.

[28] The Punch Newspaper, (December16th, 2015). Refugees and IDPs: A Twin of Common Woes. Page 26. The Punch Newspapers.

[29] The Punch Newspaper, (March, 17th, 2014) Helping Displaced People. Page26. The Punch Newspapers.

[30] The Guardian (May 13th, 2016). Boko Haram: IDP Camps Discovered in Edo State. The Guardian Newspapers.

[31] Imai, Masaaki (1986). Kaizen: The Key to Japan's Competitive Success. New York: Random House.

[32] The New York Times. ASSOCIATED PRESS. 18 November 2015. Retrieved 18 November 2015.

[33] Idogho, P. O. (2011). Higher Education in Nigeria and the Challenges Ahead. In European Journal of Educational Studies 3(2), 2011. Ozean Publication.

[34] Gantzel, K.J. (1994) 'War in the Post World War II World: Empirical Trends, Theoretical Approaches and Problems on the Concept of "ethnic war", paper presented at Symposium on Ethnicity and War, San Marino: Center for Interdisiplinary Research on Social Stress

[35] Kent, R.C. (1987) Anatomy of Disaster Relief: The International Network in Action, London: Pinter 